\title{
Gold Nanoparticles Perturb Drug-Metabolizing Enzymes and Antioxidants in the Livers of Male Rats: Potential Impact on Drug Interactions
}

This article was published in the following Dove Press journal: International Journal of Nanomedicine

Mohammed YI Al-Hamadani' Abdullah M Alzahrani (iD) Mokhtar I Yousef $\mathbb{D D}^{3}$ Maher A Kamel (iD) Wael M El-Sayed (1D)

'Department of Zoology Faculty of Science, Ain Shams University, Cairo I I566, Egypt; '2Department of Biological Sciences, King Faisal University, Ahsaa, Saudi Arabia; ${ }^{3}$ Department of Environmental Studies, Institute of Graduate Studies and Research, Alexandria University, Alexandria, Egypt; ${ }^{4}$ Department of Biochemistry, Medical Research Institute, Alexandria University, Alexandria, Egypt
Correspondence: Wael M El-Sayed

Tel $+202 / 2482-1633$

Fax +202/2684-2/23

Email wael_farag@sci.asu.edu.eg
Background and Aim: With the wide applications of chitosan and gold nanoparticles in drug delivery and many consumer products, there is limited available information about their effects on drug-metabolizing enzymes (DMEs). Changes in DMEs could result in serious drug interactions. Therefore, this study aimed to investigate the effects of exposure to chitosan or gold nanoparticles on hepatic Phase I and II DMEs, liver function and integrity, oxidative damage and liver architecture in male rats.

Methods: Animals were divided into three equal groups: a control group, a group treated with chitosan nanoparticles $(200 \mathrm{mg} / \mathrm{kg}, 50 \pm 5 \mathrm{~nm})$ and a group treated with gold nanoparticles $(4 \mathrm{mg} / \mathrm{kg}, 15 \pm 5 \mathrm{~nm}$ ). Rats were orally administered their respective doses daily for 10 days.

Results: Both chitosan and gold nanoparticles decreased the body weights by more than $10 \%$. Gold nanoparticles reduced the activities of antioxidants (superoxide dismutase and catalase), and reduced glutathione level and elevated the malondialdehyde level in the liver. Gold nanoparticles caused significant reductions in CYP1A1, CYP2E1, quinone oxidoreductase1, and glutathione S-transferase and elevated CYP2D6 and $\mathrm{N}$-acetyl transferase2. Chitosan elevated CYP2E1 and CYP2D6 and reduced UDP-glucuronosyltransferase 1A1. Both nanoparticles disturbed the architecture of the liver, but the deleterious effects after gold nanoparticles treatment were more prominent.

Conclusion: Taken together, gold nanoparticles severely perturbed the DMEs and would result in serious interactions with many drugs, herbs, and foods.

Keywords: CYP450, chitosan, drug interactions, drug metabolizing enzymes, oxidative stress

\section{Background}

The use of NPs in industry and in a wide range of consumer products is greatly increasing. ${ }^{1}$ In the biomedical field, NPs show great potential as anti-infective agents and in drug delivery, ${ }^{2}$ and as anticancer agents. ${ }^{3}$ Chitosan nanoparticles (CSNPs) are natural materials with excellent physicochemical, antimicrobial and biological characteristics, making them superior environmentally friendly materials that have been used extensively in drug delivery. ${ }^{4}$ CSNPs are favorable carriers for different drugs, particularly hydrophobic drugs, and anticancer drugs. ${ }^{5}$

Gold nanoparticles (AuNPs) have been found to be useful in a full range of applications, such as for drug delivery and the diagnostic and controlled release of chemical agents, including antioxidants, anticancer drugs, amino acids, isotopes, 
antibiotics, nucleic acids, peptides and glucose. AuNPs are the most widely studied nanoparticles with many biomedical applications due to their finely controlled shape, size, and surface chemistry. ${ }^{6}$ AuNPs are promising therapeutic agents for the treatment of $\mathrm{AIDS}^{7}{ }^{7}$ tumors $^{8}$ and Parkinson's disease. ${ }^{9}$ However, the increase in the use of these nanoparticles has caused potential concerns about possible drug interactions and unforeseen responses inside humans and other living organisms. ${ }^{10}$

Due to the widespread applications of these nanoparticles in health-care systems and polypharmacy, possible drug interactions cannot be ruled out. A drug interaction is an unintended effect of a drug due to changes in its pharmacokinetics or pharmacodynamics that could result in accumulation of the drug, toxicity and adverse effects. Drug interactions could also result in rapid elimination of the drug without achieving the therapeutic action. ${ }^{11}$

Drug-metabolizing enzymes (DMEs) play a crucial role in drug interactions. DMEs are a diverse collection of proteins that are responsible for metabolizing a vast range of xenobiotics, including drugs, pesticides, pollutants, and food toxicants. DMEs are also involved in the metabolism of endogenous compounds such as steroids and prostaglandins. ${ }^{12}$ DMEs are usually divided into 2 phases: I and II. Phase I enzymes include oxidationreduction and hydrolytic enzymes such as cytochrome P450 enzymes (CYP450s), quinone oxidoreductase (NQO1), microsomal epoxide hydrolase (mEH) and carboxylesterase (CE). Phase II enzymes include conjugative enzymes such as glutathione S-transferase (GST), UDPglucuronosyltransferases (UDPGTs), and N-acetyltransferase 2 (NAT2). ${ }^{13}$ The FDA in 2018 estimated that over two million people are hospitalized annually in the USA alone due to drug interactions resulting in about 106,000 deaths every year. Although drug discovery is a very lengthy and costly process, drug interactions caused the withdrawal of 462 medicinal products from the market between 1953 and 2013. ${ }^{14}$

There are not enough data concerning the effects of nanoparticles in general, especially CSNPs and AuNPs, on DMEs in the liver. Searching the pubmed.gov for drugmetabolizing enzymes and gold nanoparticles yielded two publications only and with chitosan yielded ZERO indicating the lack of research in this area. Therefore, the present study aimed to investigate the effects of CSNPs and AuNPs on the gene and protein levels of some key DMEs, antioxidant status, and liver function and architecture in male rats.

\section{Methods}

\section{Tested Compounds and Doses}

Chitosan nanoparticles (CSNPs, $50 \pm 5 \mathrm{~nm}$ ) and gold nanoparticles (AuNPs, $15 \pm 5 \mathrm{~nm}$ ) were purchased from Nano Tech Company (6th of October City, Giza, Egypt). The characterization of the nanoparticles is shown in Figure 1A and $\mathrm{B}$.

\section{Animals and Experimental Design}

Adult male Wistar albino rats weighing 140-160 g were used in the present study. Animals were obtained from the Faculty of Medicine, Alexandria University (Alexandria, Egypt). Animals were kept on basal diet and tap water $a d$ libitum. After an acclimation period of two weeks, the 21 animals were divided equally into 3 groups. Group 1 served as the control and received $0.3 \mathrm{~mL}$ (the same volume used in the other two groups) of isotonic saline, group 2 was administered $200 \mathrm{mg} / \mathrm{kg} \mathrm{CSNPs}{ }^{15}$ and group 3 was treated with $4 \mathrm{mg} / \mathrm{kg}$ AuNPs. ${ }^{16}$ Animals were orally treated with their respective doses daily for 10 days. The nanoparticle solutions were sonicated before use. All
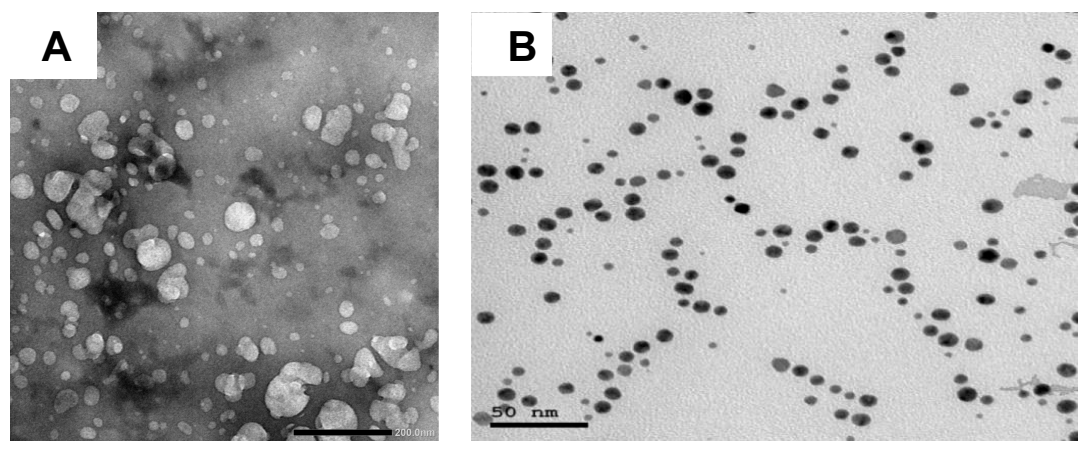

Figure I Electron micrographs showing (A) CSNPs and (B) AuNPs. 
procedures and experimental protocols were approved by the Institutional Ethics Committee at the Faculty of Science, Ain Shams University (Protocol \# 2018-AZ13 -7) and were carried out according to the criteria outlined in the "Guide for the care and use of the laboratory animals".

\section{Blood Collection and Liver Homogenate Preparation}

At the end of the experimental period, all animals were anaesthetized using isoflurane. Heparinized blood samples were collected in test tubes on ice. The blood was centrifuged at $860 \times \mathrm{g}$ for $20 \mathrm{~min}$ for the separation of plasma. The plasma was kept at $-80^{\circ} \mathrm{C}$. Two parts of the liver were removed; one part was used for histopathology, and the second part was used for total RNA extraction for the assessment of gene expression using qPCR. The remaining livers were immediately removed and perfused through the hepatic portal vein using chilled saline solution $(0.9 \%)$, and then dried and homogenized in ice-cold sucrose buffer $(0.25 \mathrm{M}, 10 \%, \mathrm{w} / \mathrm{v})$. The homogenates were centrifuged at $10,000 \times \mathrm{g}$ for $20 \mathrm{~min}$ at $4^{\circ} \mathrm{C}$, and the supernatant was collected and stored at $-80^{\circ} \mathrm{C}$.

\section{Observation of the General Health Status}

The daily routine included watching the behavior of the animals, examination of stool appearance and consistency, determination of food consumption and fluid intake, and measurement of individual body weights. All observations were normal among all groups.

\section{Biochemical Parameters}

The activities of plasma alanine aminotransferase (ALT) and aspartate aminotransferase (AST) were determined using commercial kits (Biosystems S.A. Costa Brava 30, Barcelona, Spain). The assays were performed strictly according to the procedures given by the manufacturer.

\section{Markers of Oxidative Stress}

Heating the sample with thiobarbituric acid (TBA) at a low $\mathrm{pH}$ produces a pink chromogen, and its absorbance was measured at $532 \mathrm{~nm}$. The level of thiobarbituric acid reactive substances (TBARS) was calculated from a standard curve constructed using serial concentrations of tetramethoxypropane. ${ }^{17}$ The activities of superoxide dismutase (SOD), glutathione S-transferase (GST) and catalase (CAT) in the liver homogenates were measured using colorimetric kits (Biodiagnostic,
Egypt) according to the instructions of the manufacturer. Reduced glutathione (GSH) content was assayed after protein precipitation by a metaphosphoric acid reagent. The rate of formation of 5-thio-2-nitrobenzoic acid (TNB) from GSH by 5,5'-dithiobis-(2-nitrobenzoic acid) (DTNB) was monitored at $412 \mathrm{~nm}$. The total glutathione content in the samples was determined from a GSH standard curve. ${ }^{18}$

\section{RNA Isolation and Quantitative Real-Time PCR (qPCR)}

The livers were stored in RNAlater (Qiagen, Hilden, Germany) at $-80^{\circ} \mathrm{C}$. RNA isolation was performed using an RNeasy Plus mini kit (Qiagen, Hilden, Germany). The RNA integrity and purity were determined at $260 / 280 \mathrm{~nm}$. Reverse transcription was performed using the Maxime RT PreMix kit (iNtron, Korea). This kit can simply synthesize cDNA with just a PCR machine by 2 steps in a single tube. Quantitative PCR assays were carried out using Rotor-Gene SYBR Green with a Low ROX qPCR Kit (Enzynomics, Korea). Specific primers (Life Technologies, Prague, Czech Republic) were used to determine the mRNA levels of CYP1A1, CYP2E1, CYP3A4 (CYP3A1 in rats), CYP2D6, $N A T 2, N Q O 1, C E$, UDPGT1A1, and $m E H$, in addition to the housekeeping gene GAPDH (Table 1). Measurements were performed in triplicate. The obtained data were analyzed by

Table I Sequences of Primers Used for the Real-Time PCR Analysis

\begin{tabular}{|l|l|l|}
\hline Gene & Forward Primer & Reverse Primer \\
\hline CYPIAI & 5-GAT GCT GAG GAC & 5-CAG GAG GCT GGA \\
& CAG GAA ACC GC-3 & CGA GAA TGC-3 \\
CYP2D6 & 5-GGA TGT GAC TGA & 5-TGG GGT AGG TTG \\
& 5-AGC TCT CC-3 AAC ACC & GAA GGG AC-3 \\
CYP3A4 & GCT ATG GT-3 & CTC CAT GA-3 \\
& TTT ATG-3 & 5-TTG GAG ACA GCA \\
NAT2 & 5-TAC ATT TCC CAG & ATG ATC-3 \\
& AGA TCC-3 & TGT GCT-3 \\
UDPGTIAI & 5-TCC TCA GAC GCT & 5-AGT GTG TGA TGA \\
& CCT GTG-3 & ACG CCC GA-3 \\
CE & 5-CTG GAC TTA CTT & 5-TGC AAC CAA GTC \\
& GGA AAC CC-3 & CTG GAA CA-3 \\
mEH & 5-GAC TCA CGG AGC & 5-GCC GGA TGC TCT \\
& CTA CAC TT-3 & CAT CTT CT-3 \\
NQOI & 5-CCG AAG CAT TTC & 5-TGC GTG GGC CAA \\
& AGG GTC GT-3 & TAC AAT CA-3 \\
GAPDH & 5-TCA AGA AGG TGG & 5-AGG TGG AAG AAT \\
& TGA AGC AG-3 & GGG AGT TG-3 \\
\hline
\end{tabular}


the $\Delta \Delta^{\mathrm{Ct}}$ method. ${ }^{19}$ The results were expressed as the fold change in the treatment groups relative to the control.

\section{Measurement of the DME Protein Levels in the Liver}

The ELISA kits for the determination of CYP1A1 (cat\# EKU03591), CYP2E1 (cat\# EKE620870), and CYP3A1 (cat\# EKE62407) were obtained from Biomatik Corporation (Delaware, USA). The ELISA kits for the determination of CYP2D6 (cat\# SED302Hu), NQO1 (cat\# SEL969Hu), CE (cat\# SEC374Ra) and UDPGT1A1 (cat\# SEG920Ra) were obtained from Cloud-Clone Corp (Texas, USA).

\section{Histopathological Examination}

Samples of livers from all groups were fixed in $10 \%$ formalin. Then, the samples were dehydrated in alcohol, cleared in xylene and embedded in paraffin. The liver sections were cut to a thickness of $5 \mu \mathrm{m}$. Sections were deparaffinized in xylene, rehydrated in alcohol and then rinsed in hematoxylin and eosin. ${ }^{20}$ Photographs were taken using a light Olympus microscope attached to a digital camera.

\section{Statistical Analysis}

All statistical analyses were performed using SPSS 18.1 software (Chicago, IL, USA). The results are expressed as the mean \pm SEM, $n=7$. The distribution of data was tested by the Kolmogorov-Smirnov test. The results were analyzed for statistical significance by one-way ANOVA followed by the Tukey-Kramer multiple comparisons test. Values of $\mathrm{P}<0.05$ were considered significant.

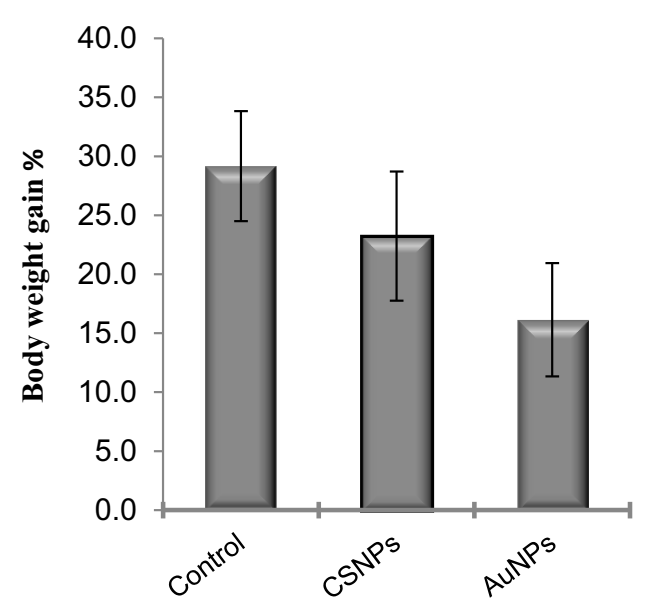

\section{Results}

The synthesized nanoparticles were characterized by different spectroscopic analyses. Gold nanoparticles appear as spherical deep-red water-soluble particles with maximum absorption at $517 \mathrm{~nm}$ and with average size (based on TEM) of $14 \pm$ $3 \mathrm{~nm}$. The chitosan nanoparticles appear as white particles suspended in water with average size of $50 \pm 5 \mathrm{~nm}$.

Administration of CSNPs or AuNPs reduced the body weight gain by $\sim 21 \%$ and $45 \%$, respectively, compared to the control. However, these reductions were statistically insignificant (Figure 2). Similarly, the liver weights were also insignificantly decreased in both groups (Figure 2).

The changes in gene expression of many xenobioticmetabolizing enzymes, including phase I and phase II enzymes, after administration of CSNPs and AuNPs were investigated (Figure 3). AuNPs significantly reduced the mRNA levels of CYP1A1, CYP2E1,CYP3A4,CE and NQO1 and elevated the expression of NAT2 by more than $200 \%$. The effects of CSNPs were less prominent; they only elevated the expression of CYP2E1 by less than 2-fold but significantly reduced the expression of UDPGT1A1. CYP2D6 was the only gene elevated by both CSNPs and AuNPs by $\sim 3$-fold (Figure 3). $m E H$ was the only gene that was devoid of any response to both CSNPs and AuNPs (data not shown).

To identify the cellular and molecular level at which these nanoparticles act, the protein levels of the genes that showed significant changes were measured in the liver by ELISA. The protein levels of CYP2E1 and CYP3A4 were not significantly affected by any treatment (data not shown). The measured protein levels of all other genes confirmed the effects seen at the mRNA

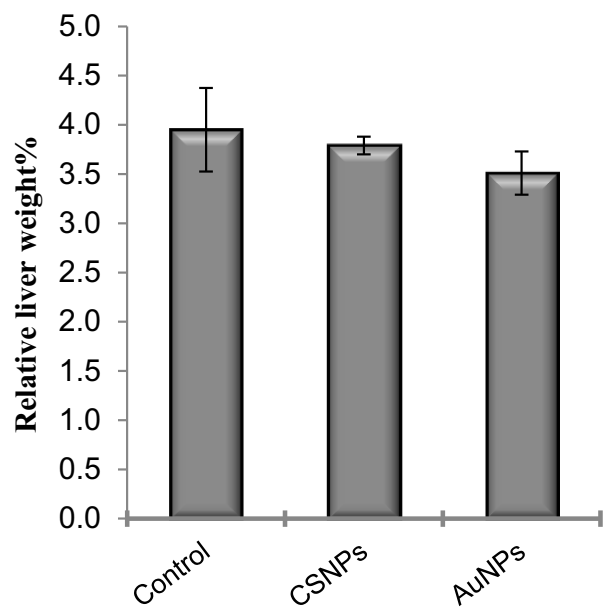

Figure 2 Effect of chitosan (CSNPs) and gold (AuNPs) nanoparticles on body weight gain\% and relative liver weight\% of adult male rats, $\mathrm{n}=7$. 

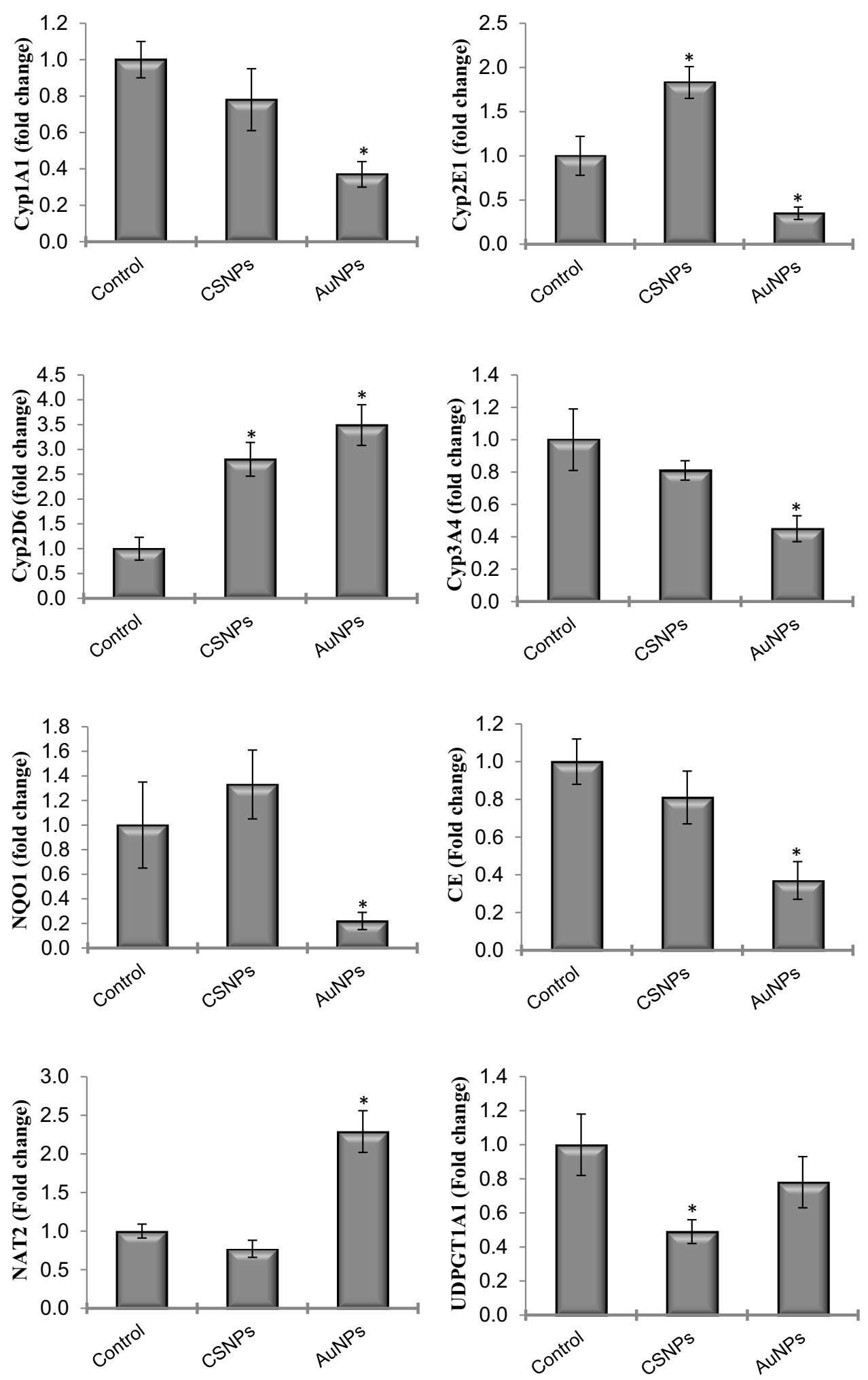

Figure 3 Effect of chitosan (CSNPs) and gold (AuNPs) nanoparticles on the gene expression of some xenobiotic-metabolizing enzymes in adult male rats, $\mathrm{n}=7$. *Significant compared to control, $\mathrm{P}<0.05$.

level (Figure 4). The protein levels of CYP1A1, CE, and NQO1 were significantly reduced in rats treated with AuNPs. AuNPs but not CSNPs significantly elevated the protein level of CYP2D6, although CSNPs elevated the gene expression of this enzyme (Figure 4). With the exception of UDPGT1A1, CSNPs were devoid of any 

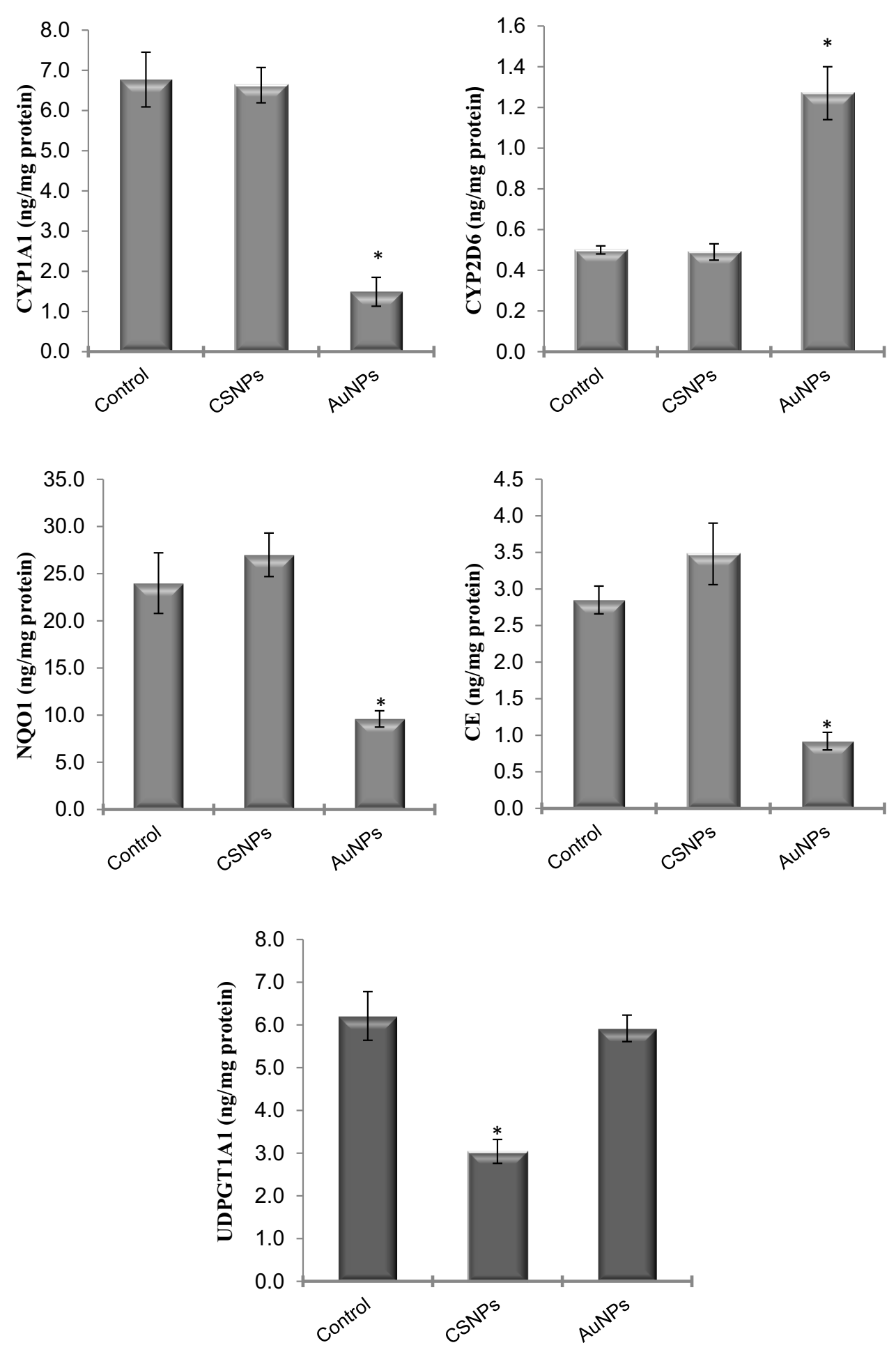

Figure 4 Effect of chitosan (CSNPs) and gold (AuNPs) nanoparticles on the protein level of some xenobiotic-metabolizing enzymes in adult male rats, $\mathrm{n}=7$. *Significant compared to control, $\mathrm{P}<0.05$.

significant effect on the proteins investigated. Consistent with its effect on gene expression, CSNPs reduced the protein level of UDPGT1A1 by $\sim 50 \%$ (Figure 4 ). The protein level of NAT2 was not measured in the current study.
Changes in the plasma ALT and AST activities and albumin level in animals treated with CSNPs or AuNPs did not achieve statistical significance (Table 2). CSNPs did not cause any significant changes to the antioxidants measured (SOD, GST, catalase, and GSH) or MDA in the 
Table 2 Effect of Chitosan (CSNPs) and Gold (AuNPs) Nanoparticles on Liver Functions and Oxidative Stress

\begin{tabular}{|l|l|l|l|}
\hline & Control & CSNPs & AuNPs \\
\hline ALT (U/L) & $24.2 \pm 1.2$ & $30.6 \pm 2.2$ & $29.6 \pm 3.5$ \\
\% Change & & $\uparrow 26.5$ & $\uparrow 22.5$ \\
AST (U/L) & $50.3 \pm 4.3$ & $33.5 \pm 3.3$ & $46.2 \pm 3.4$ \\
\% Change & & $\downarrow 27.9$ & $\downarrow 8.2$ \\
Albumin (g/dl) & $4.9 \pm 0.3$ & $4.26 \pm 0.4$ & $4.3 \pm 0.4$ \\
\% Change & & $\downarrow 13.6$ & $\downarrow 12.4$ \\
SOD (U/mg protein) & $65.3 \pm 4.9$ & $57.3 \pm 1.8$ & $24.0 \pm 4.0^{*}$ \\
\% Change & & $\downarrow 12.3$ & $\downarrow 63.2$ \\
CAT (U/mg protein) & $46.3 \pm 3.5$ & $50.3 \pm 1.5$ & $18.0 \pm 2.1^{*}$ \\
\% Change & & $\uparrow 8.6$ & $\downarrow 61.1$ \\
GST (U/mg protein) & $48.7 \pm 2.6$ & $51.0 \pm 5.2$ & $20.7 \pm 4.1^{*}$ \\
\% Change & & $\uparrow 4.7$ & $\downarrow 57.5$ \\
GSH (mmol/g tissue) & $41.7 \pm 3.8$ & $42.3 \pm 3.9$ & $14.7 \pm 2.0^{*}$ \\
\% Change & & $\uparrow 1.4$ & $\downarrow 64.7$ \\
MDA (nmol/g tissue) & $13.2 \pm 0.8$ & $18.7 \pm 0.8$ & $24.5 \pm 2.7^{*}$ \\
\% Change & & $\uparrow 41.7$ & $\uparrow 85.6$ \\
\hline
\end{tabular}

Notes: Data are expressed as mean \pm SEM, $n=7$; *Significant difference compared to control at $\mathrm{p}<0.05$.

liver. AuNPs caused significant reductions $(\sim 60 \%)$ in all antioxidants investigated and a significant elevation $(\sim 85 \%)$ in MDA level in the liver (Table 2).

The gene expression of CYPIA1 was positively and strongly correlated with the activities of hepatic SOD and catalase and GSH level. The protein level of CYP1A1 was positively correlated with the protein levels of NQO1 and CE. The CYP2D6 protein level was negatively correlated with the protein levels of CYP1A1, NQO1 and CE and positively correlated with CYP2E1. The protein level of NQO1 was positively correlated with that of CE (Figure 5).

Administration of CSNPs caused marked dilation of the central vein and portal tract with few infiltrating lymphocytes in liver lobules and marked sinusoidal dilation. Some hepatocytes appeared with vacuolated nuclei. AuNPs also caused marked dilatation of the central vein with infiltrating lymphocytes and fibrosis surrounding the portal tract with hemorrhage. The liver lobules showed densely stained pyknotic nuclei and a few necrotic nuclei (Figure 6).

\section{Discussion}

Some gold nanoformulations are in clinical trials for photothermal therapy for tumors. ${ }^{21}$ CSNPs are already in used in many cosmetics as well as nanocarriers for some medicines. ${ }^{22}$ Therefore, humans are already exposed to these nanoparticles and are expected to be heavily exposed in the next decades. One of the major problems in drug discovery is unintended drug interactions. These result from the inhibition or induction of key drug-metabolizing enzymes. Drug interactions are responsible for many fatalities and/or socioeconomic burdens. ${ }^{23}$ Therefore, the present study aimed to evaluate the effect of AuNPs and CSNPs on the major drug-metabolizing enzymes (DMEs). Although AuNPs and CSNPs are used for drug delivery and/or imaging through oral or intravenous routes, yet most drugs are taken orally. In addition, through this oral route the drugs will pass to the liver which is the main organ that contains the drugmetabolizing enzymes. Therefore, the current study focused on the oral administration of these nanoparticles. First, we assessed the effects of AuNPs and CSNPs on the expression levels of nine genes coding for major DMEs, and then we estimated the effects on the protein levels of these enzymes. The levels of nine key phase I and phase II DMEs (CYP1A1, CYP3A1 (3A4), CYP2D6, CYP2E1, mEH, NQO1, UDPGT1A1, CE, and NAT2) were measured in the liver (the main organ for drug metabolism). The liver, due to many structural and functional factors, is the main organ exposed to exogenous as well as endogenous chemicals and pollutants. ${ }^{24,25}$ The cytochrome P450 (CYP) system is the largest and most important enzyme superfamily for drug metabolism and plays a key role in the detoxification and clearance of a wide range of xenobiotics and endogenous substances. They are also involved in the metabolism of many steroid hormones, eicosanoids and fatty acids. ${ }^{26}$ Approximately $85 \%$ of drugs currently in use in addition to other lipophilic xenobiotics are primarily metabolized by these microsomal enzymes in humans. ${ }^{27,28}$ Therefore, any change in the expression of these enzymes would greatly affect the drug metabolism resulting in serious drug interactions. The P450 profiling is a mandatory file for approval of new drugs by the FDA. There are limited data available on the induction/inhibition of certain CYPs by nanoparticles, including metallic and polymeric nanomaterials. NQO1 reduces the quinones such as ubiquinone and benzoquinone, to hydroquinones through two-electron reduction. ${ }^{29}$ Changes in this enzyme have been linked to different forms of cancers, Alzheimer's disease, and oxidative stress as well as drug interactions. ${ }^{30}$ Carboxyl esterases hydrolyze carboxylic esters into alcohol and carboxylate. The latter is conjugated and excreted. They play a crucial role in the metabolism of neurotransmitters and many pesticides. Acetylcholine esterase is an important example from this family. ${ }^{31}$ NAT2 metabolizes many arylamines and hydrazine drugs as well as many carcinogens. ${ }^{32}$ The main function of phase II DMEs is the conjugation which makes the substrates more water 

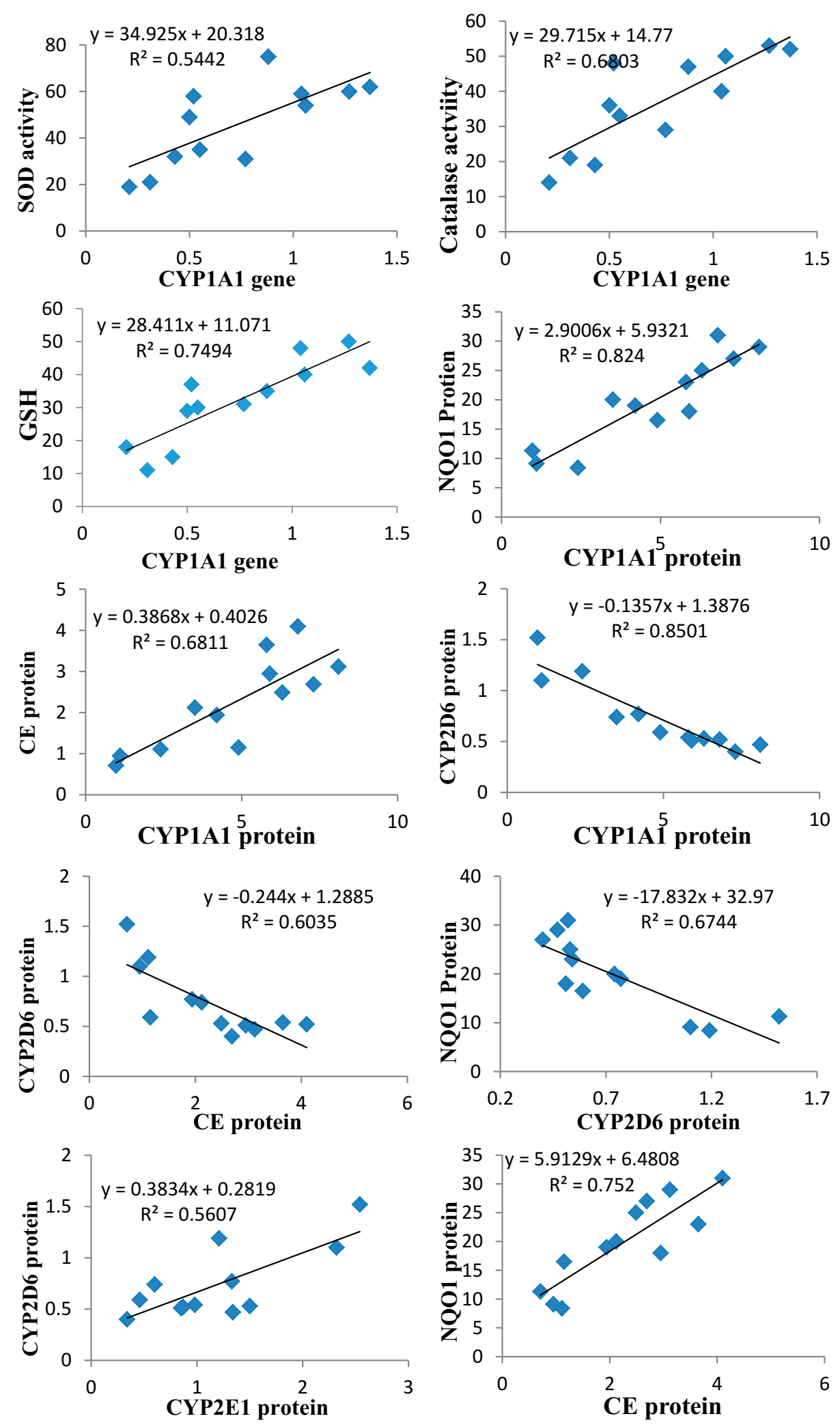

Figure 5 The Pearson significant correlations between different parameters (different proteins and genes of the drug-metabolizing enzymes, antioxidant enzymes, and reduced glutathione). 

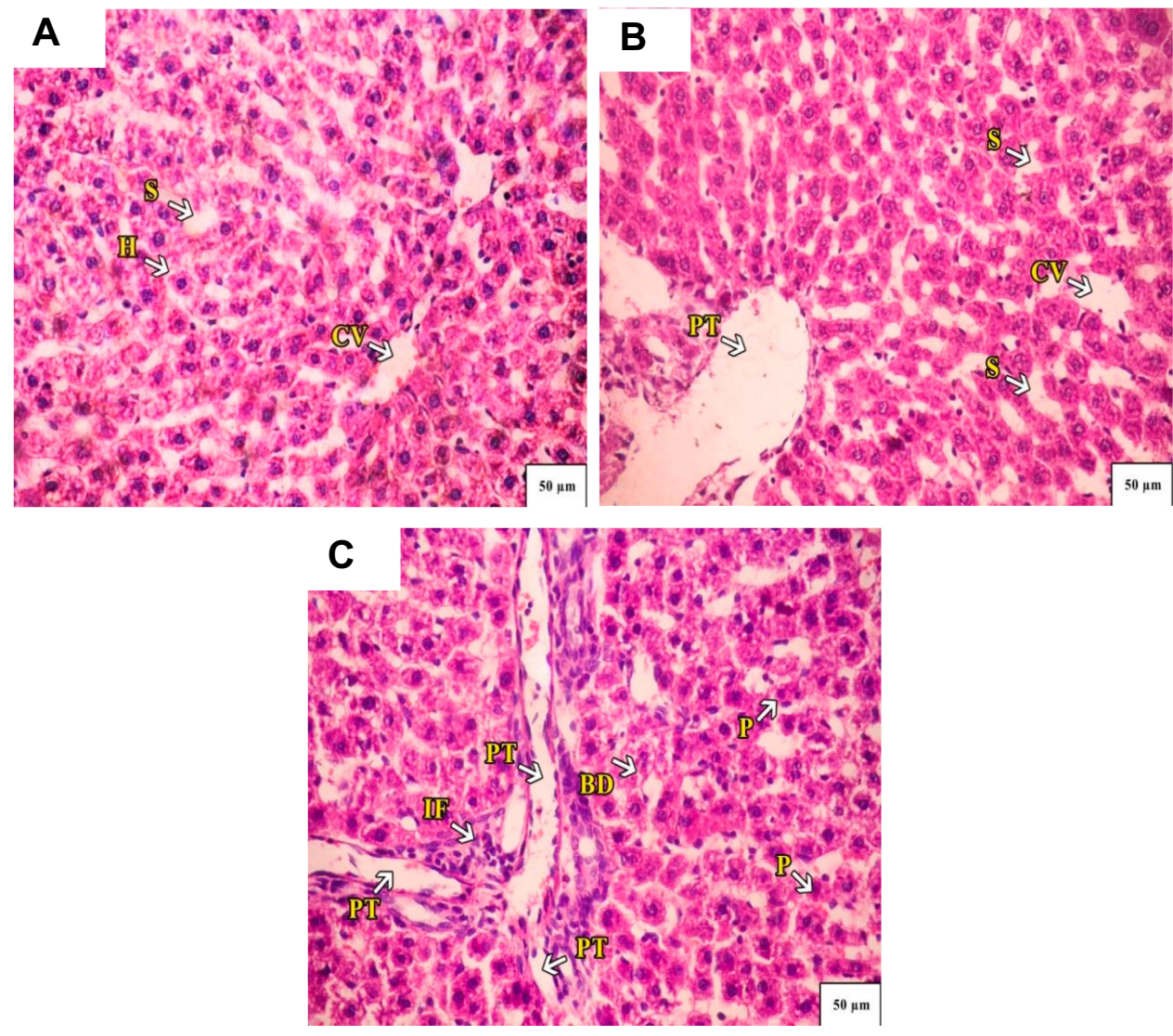

Figure 6 (A) A Photograph of control rat liver. The hepatocytes radiate from the central vein $(\mathrm{CV})$ toward the periphery of the lobule. Normal hepatocytes $(\mathrm{H})$ with milddilated blood sinusoids (S) are seen. (B) A photograph of rat liver administered with chitosan, a marked dilation of central vein (CV) and portal tract (PT), there are few infiltrating lymphocytes in liver lobules, marked sinusoidal dilation (S). Some hepatocytes appear with vacuolated nuclei. (C) A photograph of rat liver administered with AuNPs. A marked dilation of central vein (CV), and infiltrating lymphocytes and fibrosis (IF) surrounding the portal tract (PT) with hemorrhage along with mild-dilated bile duct $(B D)$ are seen. The liver lobules showed densely stained pyknotic nuclei $(P)$ and few necrotic nuclei. H\&E stain $40 x$.

soluble and thus helps in their safe elimination. GSTs are primarily involved in the conjugation and removal of electrophilic xenobiotics. They play a significant role in antioxidant defense and they also have a unique role in chemotherapeutic resistance of cancer cells. ${ }^{33}$ Although UDPGT1A1 is mainly involved in the bilirubin metabolism, it also plays a significant role in the metabolism of many drugs such as irinotecan. ${ }^{34}$

The present study showed that AuNPs significantly reduced the expression of CYP1A1, CYP2E1, CYP $3 A 4$, $C E$ and NQO1 and elevated the expression of NAT2. Treatment with AuNPs or CSNPs elevated the expression of CYP2D6. Treating animals with CSNPs elevated the expression of CYP2E1 but reduced the expression of UDPGT1A1. It has been found that AuNPs accumulate in the liver and spleen, affecting the gene expression of many enzymes. ${ }^{35,36}$ Hepatic P450s are primarily involved in the synthesis and/or metabolism of endogenous and exogenous compounds. ${ }^{37,38}$ CYP450 enzymes are the main players in drug and metabolite clearance. Therefore, inhibition of CYP450s leads to drug-drug interactions and toxicity, ${ }^{39}$ while their induction increases drug elimination and reduces drug efficacy. ${ }^{40}$ Therefore, the numbers of drugs/xenobiotics that will be affected by these induction and inhibition effects on various CYPs are enormous. Inhibition of CYPs would result in serious adverse effects of almost all classes of drugs, including analgesics, anesthetics, immunosuppressants, antivirals, antibiotics, antifungals, anticancer agents, antidepressants, antihypertensives, statins, and antacids. ${ }^{41}$ This would also affect the metabolism of endogenous molecules such as neurotransmitters and hormones. This would also result in the accumulation and toxicity of pesticides and agrochemicals in the body. ${ }^{42}$ It has been shown that silver nanoparticles exhibit strong inhibitory effects on the biotransformation activity of the human CYP3A family. ${ }^{43,44}$

Elevations in NAT2 and CYP2D6 would cause the rapid elimination of target xenobiotics/drugs and failure of therapy. CYP2D6 alone is responsible for the metabolism of 
approximately $25 \%$ of clinically administered drugs. ${ }^{43}$ The measured protein levels of almost all genes confirmed the effects seen at the mRNA levels. The protein levels of CYP2E1 and CYP3A4 were not significantly affected by any treatment. A linear correlation between gene expression and protein expression does not always exist due to the complexity of steps involved in the transcription, posttranscription, translation and post-translation processes.

The hepatotoxicity of AuNPs may be attributed to the accumulation of nanoparticles in the liver ${ }^{45}$ but unfortunately, we have not measured the level of AuNPs in liver in the current study. The differential sensitivity of these major CYP isozymes to inhibition by AuNPs may be attributed to the structural diversity, heterogeneity, and plasticity among eukaryotic microsomal CYPs. ${ }^{46}$ AuNPs with a larger curvature had a stronger inhibitory effect on CYPs. ${ }^{47}$ AuNPs influenced the catalytic activity of CYP enzymes at the cellular and molecular levels in vivo and in vitro. ${ }^{36,48-50}$ Since most of these enzymes are regulated by nuclear orphan receptors, binding to these receptors cannot be ruled out as a possible mechanism that needs further investigation.

AuNPs induced oxidative stress in the liver tissues that led to the accumulation of free radicals and thereby reduced the activities of liver antioxidant enzymes (SOD, CAT, and GST) and GSH level. Treatment of rats with CSNPs and AuNPs increased MDA level, indicating lipid peroxidation. In a previous study, AuNPs induced oxidative stress in the liver and caused hepatic tissue damage. ${ }^{51}$ The increase in MDA levels in the liver from CSNP- and AuNP-treated rats might indirectly lead to an increase in oxidative DNA damage. $^{52,53}$ Some studies have reported that the administration of metal oxide particles leads to oxidative stress, cell changes and death, and DNA destruction. ${ }^{54,55} \mathrm{~A}$ previous study found that IP administration of AuNPs $(10 \mathrm{~nm})$ for three days elevated antioxidant levels but these levels were reduced after seven days of treatment. ${ }^{56}$

It has been reported that nanoparticles initiate reactive oxygen species (ROS) production, leading to oxidative stress, while the redox state of the cell is imbalanced. ${ }^{57}$ ROS induction by nanoparticles is considered the number one mode of nanotoxicity and has been attributed to the presence of prooxidant groups on their reactive surface or because of nanoparticle-cell interactions. In the present study, AuNPs reduced all the antioxidants studied. Intraperitoneal injection of AuNPs into mice decreased catalase and glutathione peroxidase in healthy and diabetic mice. ${ }^{58}$ It was found that ROS production increased with the increase in the concentration of nanoparticles. ${ }^{59}$ It was also concluded that the toxicity of AuNPs depends on their ability to trigger the intracellular formation of ROS from dioxygen. ${ }^{60}$

Nanoparticles in the current study did not cause any significant changes in the activities of ALT and AST or albumin level, which is in accordance with a previous study. ${ }^{59}$ However, administration of AuNPs caused severe changes in the architecture of the liver, as evidenced by the histopathological examination in accordance with a previous study. ${ }^{61}$ CSNPs also caused some tissue deterioration but this was much less than that caused by AuNPs. Hepatic tissue deterioration confirmed the biochemical changes reported in the present study.

The gene expression of CYP1A1 was positively and strongly correlated with the activities of hepatic SOD and catalase and GSH level. The protein level of CYP1A1 was positively correlated with the protein levels of NQO1 and CE. The CYP2D6 protein level was negatively correlated with the protein levels of CYP1A1, NQO1 and CE and positively correlated with CYP2E1. Crosstalk between different transcription factors, such as $\mathrm{AhR}$ and $\mathrm{Nrf} 2$, could be responsible for the correlation between different antioxidants (NQO1, SOD, catalase and CE) and CYP1A1. AhR is responsible for the induction of different CYPs (CYP1A1 in particular), and Nrf2, through binding to Antioxidant Response Elements (AREs), is responsible for the induction of many antioxidant enzymes. ${ }^{62}$ However, all these hypotheses remain speculative and need further studies to explain the possibility that nanoparticles could be ligands of different orphan nuclear receptors.

To conclude, gold nanoparticles, although examined at a low dose, perturbed many phase I drug-metabolizing enzymes with the potential to cause serious drug interactions. These particles also disturbed the antioxidant milieu of the liver by reducing many antioxidants. This was reflected by the architecture of the liver tissue. Although CSNPs caused some disturbances, the deleterious effects after AuNP treatment were more prominent. Taken together, caution must be taken when using AuNPs as a medicine or in cosmetics. CSNPs were safer than AuNPs in the current study. Further studies are required to identify the molecular pathways and possible target receptors and transcription factors of these nanoparticles.

\section{Funding}

This project was supported by King Faisal University, Deanship of Scientific Research, grant 180124. 


\section{Disclosure}

The authors declare no conflicts of interest.

\section{References}

1. Stampoulis D, Sinha SK, White JC. Assay-dependent phytotoxicity of nanoparticles to plants. Environ Sci Technol. 2009;43 (24):9473-9479. doi:10.1021/es901695c

2. Seil JT, Webster TJ. Antimicrobial applications of nanotechnology: methods and literature. Int $J$ Nanomedicine. 2012;7:2767-2781. doi: $10.2147 /$ IJN.S24805

3. Jahangirian H, Lemraski EG, Webster TJ, Rafiee-Moghaddam R, Abdollahi Y. A review of drug delivery systems based on nanotechnology and green chemistry: green nanomedicine. Int $J$ Nanomedicine. 2017;12:2957-2978. doi:10.2147/IJN.S127683

4. Ilk S, Sağlam N, Özgen M, Korkusuz F. Chitosan nanoparticles enhances the anti-quorum sensing activity of kaempferol. Int $J$ Biol Macromol. 2017;94:653-662. doi:10.1016/j.ijbiomac.2016.10.068

5. Rajan M, Raj V. Potential drug delivery applications of chitosan based nanomaterials. Int Revi Chem Eng. 2013;5(2):145-155.

6. Li N, Zhao P, Astruc D. Anisotropic gold nanoparticles: synthesis, properties, applications, and toxicity. Angew Chem Int Ed Engl. 2014;53(7):1756-1789.

7. Bowman MC, Ballard TE, Ackerson CJ, Feldheim DL, Margolis DM, Melander C. Inhibition of HIV fusion with multivalent gold nanoparticles. J Am Chem Soc. 2008;130(22):6896-6897. doi:10.1021/ja710321g

8. Kennedy LC, Bickford LR, Lewinski NA, et al. A new era for cancer treatment: gold-nanoparticle-mediated thermal therapies. Small. 2011;7(2):169-183. doi:10.1002/smll.201000134

9. Kogan MJ, Bastus NG, Amigo R, et al. Nanoparticle-mediated local and remote manipulation of protein aggregation. Nano Lett. 2006;6 (1):110-115. doi:10.1021/n10516862

10. Fernández-Iglesias N, Bettmer J. Complementary mass spectrometric techniques for the quantification of the protein corona: a case study on gold nanoparticles and human serum proteins. Nanoscale. 2015;7 (34):14324-14331. doi:10.1039/C5NR02625C

11. Gallelli L, Colosimo M, Tolotta GA, et al. Prospective randomized double-blind trial of racecadotril compared with loperamide in elderly people with gastroenteritis living in nursing homes. Eur $J$ Clin Pharmacol. 2010;66(2):137-144. doi:10.1007/s00228-0090751-3

12. Rendic S, Guengerich FP. Update information on drug metabolism systems-2009, part II: summary of information on the effects of diseases and environmental factors on human cytochrome P450 (CYP) enzymes and transporters. Curr Drug Metab. 2010;11 (1):4-84. doi:10.2174/138920010791110917

13. Iyanagi T. Molecular mechanism of phase I and phase II drug-metabolizing enzymes: implications for detoxification. Int Rev Cytol. 2007;260:35-112.

14. Onakpoya IJ, Heneghan CJ, Aronson JK. Post-marketing withdrawal of 462 medicinal products because of adverse drug reactions: a systematic review of the world literature. BMC Med. 2016;14 (1):10. doi:10.1186/s12916-016-0553-2

15. Ozcelik E, Uslu S, Erkasap N, Karimi H. Protective effect of chitosan treatment against acetaminophen-induced hepatotoxicity. Kaohsiung J Med Sci. 2014;30(6):286-290. doi:10.1016/j.kjms.20 14.02.003

16. Zhang XD, Wu D, Shen X, et al. Size-dependent radiosensitization of PEG-coated gold nanoparticles for cancer radiation therapy. Biomaterials. 2012;33(27):6408-6419. doi:10.1016/j.biomaterials.20 12.05.047

17. Draper HH, Hadley M. Malondialdehyde determination as index of lipid peroxidation. Methods Enzymol. 1990;186:421-431.
18. Griffith OW. Determination of glutathione and glutathione disulfide using glutathione reductase and 2-vinylpyridine. Anal Biochem. 1980;106(1):207-212. doi:10.1016/0003-2697(80)901 39-6

19. Livak KJ, Schmittgen TD. Analysis of relative gene expression data using real-time quantitative PCR and the $2-\Delta \Delta \mathrm{CT}$ method. Methods. 2001;25(4):402-408. doi:10.1006/meth.2001.1262

20. Bancroft JD, Stevens A. Theory and Practice of Histological Techniques. 6th ed. Edinburgh: Churchill Livingstone; 2008.

21. Singh P, Pandit S, Mokkapati VRSS, Garg A, Ravikumar V, Mijakovic I. Gold nanoparticles in diagnostics and therapeutics for human cancer. Int J Mol Sci. 2018;19(7):1979. doi:10.3390/ijms19 071979

22. Aranaz I, Acosta N, Civera C, et al. Cosmetics and cosmeceutical applications of chitin, chitosan and their derivatives. Polymers. 2018;10(2):213. doi:10.3390/polym10020213

23. Li Y, Meng Q, Yang M, et al. Current trends in drug metabolism and pharmacokinetics. Acta Pharm Sin B. 2019;9(6):1113-1144. doi:10.1016/j.apsb.2019.10.001

24. Boyles MS, Kristl T, Andosch A, et al. Chitosan functionalisation of gold nanoparticles encourages particle uptake and induces cytotoxicity and pro-inflammatory conditions in phagocytic cells, as well as enhancing particle interactions with serum components. J Nanobiotechnol. 2015;13:84. doi:10.1186/s12951-015-0146-9

25. Stavropoulou E, Pircalabioru GG, Bezirtzoglou E. The role of cytochromes P450 in infection. Front Immunol. 2018;9:89. doi:10.3389/ fimmu.2018.00089

26. Gu X, Manautou JE. Molecular mechanisms underlying chemical liver injury. Expert Rev Mol Med. 2012;14:e4. doi:10.1017/ S1462399411002110

27. Guengerich FP. Cytochrome p450 and chemical toxicology. Chem Res Toxicol. 2008;21(1):70-83. doi:10.1021/tx700079z

28. Balaz S. Modeling kinetics of subcellular disposition of chemicals. Chem Rev. 2009;109(5):1793-1899. doi:10.1021/ cr030440j

29. Lajin B, Alachkar A. The NQO1 polymorphism C609T (Pro187Ser) and cancer susceptibility: a comprehensive meta-analysis. $\mathrm{Br}$ J Cancer. 2013;109:1325-1337. doi:10.1038/bjc.2013.357

30. Wang $\mathrm{B}$, Jin F, Xie $\mathrm{Y}$, et al. Association analysis of $\mathrm{NAD}(\mathrm{P}) \mathrm{H}$ : quinone oxidoreductase gene $609 \mathrm{C} / \mathrm{T}$ polymorphism with Alzheimer's disease. Neurosci Lett. 2006;409(3):179-181. doi:10.10 16/j.neulet.2006.09.042

31. Taylor P, Radić Z. The cholinesterases: from genes to proteins. Ann Rev Pharmacol Toxicol. 1994;34:281-320. doi:10.1146/annurev. pa.34.040194.001433

32. Agúndez JA. N-Acetyltransferases: lessons learned from eighty years of research. Curr Drug Metab. 2008;9(6):463-464. doi:10.2174/ 138920008784892146

33. Hayes JD, Flanagan JU, Jowsey IR. Glutathione transferases. Ann Rev Pharmacol Toxicol. 2005;45(1):51-88. doi:10.1146/annurev. pharmtox.45.120403.095857

34. Tukey RH, Strassburg CP. Human UDP-glucuronosyltransferases: metabolism, expression, and disease". Annu Rev Pharmacol Toxicol. 2000;40:581-616. doi:10.1146/annurev.pharmtox.40.1.581

35. Balasubramanian SK, Jittiwat J, Manikandan J, Ong CN, Yu LE, Ong WY. Biodistribution of gold nanoparticles and gene expression changes in the liver and spleen after intravenous administration in rats. Biomaterials. 2010;31(8):2034-2042. doi:10.1016/j.biomaterials.2009. 11.079

36. Cho WS, Cho M, Jeong J, et al. Size-dependent tissue kinetics of PEG-coated gold nanoparticles. Toxicol Appl Pharmacol. 2010;245 (1):116-123. doi:10.1016/j.taap.2010.02.013

37. Hwang JH, Kim SJ, Kim YH, et al. Susceptibility to gold nanoparticle-induced hepatotoxicity is enhanced in a mouse model of nonalcoholic steatohepatitis. Toxicology. 2012;294(1):27-35. doi:10.1016/j.tox.2012.01.013 
38. Chen J, Wang H, Long W, et al. Sex differences in the toxicity of polyethylene glycol-coated gold nanoparticles in mice. Int J Nanomedicine. 2013;8:2409-2419. doi:10.2147/IJN.S46376

39. Fowler S, Zhang H. In vitro evaluation of reversible and irreversible cytochrome P450 inhibition: current status on methodologies and their utility for predicting drug-drug interactions. AAPS J. 2008;10 (2):410-424. doi:10.1208/s12248-008-9042-7

40. Lazarou J, Pomeranz BH, Corey PN. Incidence of adverse drug reactions in hospitalized patients: a meta-analysis of prospective studies. JAMA. 1998;279(15):1200-1205. doi:10.1001/jama.279.15.1200

41. Bibi Z. Role of cytochrome P450 in drug interactions. Nutr Metab. 2008;5:27. doi:10.1186/1743-7075-5-27

42. Lushchak VI, Matviishyn TM, Husak VV, Storey JM, Storey KB. Pesticide toxicity: a mechanistic approach. EXCLI J. 2018;17: 1101-1136. doi:10.17179/excli2018-1710

43. Kulthong K, Maniratanachote R, Kobayashi Y, Fukami T, Yokoi T. Effects of silver nanoparticles on rat hepatic cytochrome $\mathrm{P} 450$ enzyme activity. Xenobiotica. 2012;42(9):854-862. doi:10.3109/ 00498254.2012 .670312

44. Lamb JG, Hathaway LB, Munger MA, Raucy JL, Franklin MR. Nanosilver particle effects on drug metabolism in vitro. Drug Metab Dispos. 2010;38(12):2246-2251. doi:10.1124/dmd.110.035238

45. Khan HA, Abdelhalim MA, Al-Ayed MS, Alhomida AS. Effect of gold nanoparticles on glutathione and malondialdehyde levels in liver, lung and heart of rats. Saudi J Biol Sci. 2012;19(4):461-464. doi:10.1016/j.sjbs.2012.06.005

46. Johnson EF, Stout CD. Structural diversity of eukaryotic membrane cytochrome p450s. J Biol Chem. 2013;288(24):17082-17090. doi:10.1074/jbc.R113.452805

47. Wu Z, Zhang B, Yan B. Regulation of enzyme activity through interactions with nanoparticles. Int J Mol Sci. 2009;10(10):419 8-4209. doi:10.3390/ijms10104198

48. Sereemaspun A, Hongpiticharoen P, Rojanathanes R, Maneewattanapinyo P, Ekgasit S, Warisnoicharoen W. Inhibition of human cytochrome P450 enzymes by metallic nanoparticles: a preliminary to nanogenomics. Int $J$ Pharmacol. 2008;4 (6):492-495. doi:10.3923/ijp.2008.492.495

49. Ye M, Tang L, Luo M, et al. Size- and time-dependent alteration in metabolic activities of human hepatic cytochrome P450 isozymes by gold nanoparticles via microsomal coincubations. Nanoscale Res Lett. 2014;9(1):642. doi:10.1186/1556-276X-9-642

50. Choi K, Riviere JE, Monteiro-Riviere NA. Protein corona modulation of hepatocyte uptake and molecular mechanisms of gold nanoparticle toxicity. Nanotoxicology. 2017;11(1):64-75. doi:10.1080/17435390. 2016.1264638
51. Adetoro KO, Bolanle JD, Abdullahi SB, Ahmed OA. In vivo antioxidant effect of aqueous root bark, stem bark and leaves extracts of Vitex doniana in $\mathrm{CCl} 4$ induced liver damage rats. Asian Pac J Trop Biomed. 2013;3(5):395-400. doi:10.1016/S2221-1691(13)60083-0

52. El-Nekeety AA, Abdel-Azeim SH, Hassan AM, Hassan NS, Aly SE, Abdel-Wahhab MA. Quercetin inhibits the cytotoxicity and oxidative stress in liver of rats fed aflatoxin-contaminated diet. Toxicol Rep. 2014;1:319-329. doi:10.1016/j.toxrep.2014.05.014

53. El-Bahr SM. Effect of curcumin on hepatic antioxidant enzymes activities and gene expressions in rats intoxicated with aflatoxin B1. Phytother Res. 2015;29(1):134-140. doi:10.1002/ptr.5239

54. Borm PJ, Robbins D, Haubold S, et al. The potential risks of nanomaterials: a review carried out for ECETOC. Part Fibre Toxicol. 2006;3:11. doi:10.1186/1743-8977-3-11

55. Ghosh P, Han G, De M, Kim CK, Rotello VM. Gold nanoparticles in delivery applications. Adv Drug Deliv Rev. 2008;60(11):1307-1315. doi:10.1016/j.addr.2008.03.016

56. Abdelhalim MA, Al-Ayed MS, Moussa SA. The effects of intraperitoneal administration of gold nanoparticles size and exposure duration on oxidative and antioxidants levels in various rat organs. Pak J Pharm Sci. 2015;28(2):705-712.

57. Sarkar A, Ghosh M, Sil PC. Nanotoxicity: oxidative stress mediated toxicity of metal and metal oxide nanoparticles. J Nanosci Nanotechnol. 2014;14(1):730-743. doi:10.1166/jnn.2014.8752

58. Selim ME, Hendi AA, Alfallaj E. The possible counteractive effect of gold nanoparticles against streptozotocin-induced type 1 diabetes in young male albino rats. Pak J Pharm Sci. 2016;29(3):823-836.

59. Liu Z, Liu S, Ren G, Zhang T, Yang Z. Nano-CuO inhibited voltage-gated sodium current of hippocampal CA1 neurons via reactive oxygen species but independent from G-proteins pathway. $J$ Appl Toxicol. 2011;31(5):439-445. doi:10.1002/jat.1611

60. Pan Y, Leifert A, Ruau D, et al. Gold nanoparticles of diameter 1.4 $\mathrm{nm}$ trigger necrosis by oxidative stress and mitochondrial damage. Small. 2009;5(18):2067-2076.

61. Ibrahim KE, Al-Mutary MG, Bakhiet AO, Khan HA. Histopathology of the liver, kidney, and spleen of mice exposed to gold nanoparticles. Molecules. 2018;23:1848. doi:10.3390/molecules23081848

62. Shin S, Wakabayashi N, Misra V, et al. NRF2 modulates aryl hydrocarbon receptor signaling: influence on adipogenesis. Mol Cell Biol. 2007;27(20):7188-7197. doi:10.1128/MCB.00915-07
International Journal of Nanomedicine

\section{Publish your work in this journal}

The International Journal of Nanomedicine is an international, peerreviewed journal focusing on the application of nanotechnology in diagnostics, therapeutics, and drug delivery systems throughout the biomedical field. This journal is indexed on PubMed Central, MedLine, CAS, SciSearch ${ }^{\mathbb{R}}$, Current Contents ${ }^{\mathbb{R}} /$ Clinical Medicine, $^{2}$
Journal Citation Reports/Science Edition, EMBase, Scopus and the Elsevier Bibliographic databases. The manuscript management system is completely online and includes a very quick and fair peer-review system, which is all easy to use. Visit http://www.dovepress.com/ testimonials.php to read real quotes from published authors. 